\title{
A STUDY ON ACADEMIC ANXIETYAMONG SECONDARY SCHOOL STUDENTS IN AIZAWL DISTRICT
}

\author{
${ }^{1}$ M.S.Dawngliani, ${ }^{2}$ Prof. Lallianzuali Fanai, ${ }^{3}$ Dr. Vanlaltanpuii \\ ${ }^{1}$ Research Scholar, ${ }^{2}$ Professor, ${ }^{3}$ Assoc. Professor. \\ MA (Edu.) \\ 1913(P) IGNOU Centre, Institute of Advanced Studies in Education, Republic Veng, \\ Aizawl Mizoram 796005
}

Article DOI: https://doi.org/10.36713/epra6702

DOI No: 10.36713/epra6702

\begin{abstract}
The aim of this research is to study Academic Anxiety among secondary school students in Aizawl District. For this purpose, the sample was selected from different secondary school within Aizawl District. The sample consisted of 90 students. Out of 90 students, 47 male students and 43 female students were taken.60 students form Urban and 30 from Rural areas while 45 each from class 9 and 10. Academic Anxiety Scale (AAS-Samrua) developed by Dr. Mohd. Abid Siddiqui and Dr. Atieq UI Rehman was used as a tool for data collection. Mean and t-test were used to analyzed the data. The findings of the study reveal that no significant difference was found in in relation to gender, Class and Locality. There is Above Average level of Academic Anxiety of secondary school students.

KEYWORDS - Academic anxiety, gender, class, locality.
\end{abstract}

\section{INTRODUCTION}

Anxiety disorders are the most common disorders that occur during adolescence. Anxiety can be of different types and academic anxiety is one of the anxieties. Academic anxiety is a kind of anxiety related to the learning institution, learning environment, ineffective study habits, a certain subject, the specific subject teacher or from the examination. It is a mutual feeling of nervousness, uneasiness, distress, stress or tension in a reaction to a certain school situation which is related to the academics

Anxiety is reasonable thing. It is right that a high level of anxiety hinders with concentration and memory. Without any anxiety, however, most of us would lack the motivation. A reasonable amount of anxiety truly benefits generating motivation. It plays significant parts in our lives and also a normal reaction to certain situations. A minor level of anxiety is usual, but severe anxiety can be a serious problem.
Academic anxiety is a sort of state anxiety which relates to the approaching danger from the environments of the academic institutions including teacher, certain subjects like Mathematics, English, etc. Academic anxiety can significant by the way of influencing the learners' mind set in the form of motivation to the academic success of the students while can be a factor to come down the academic achievement of student, so there is need to manage academic anxiety to improve the academic performance. If a student has social anxiety, the student might not be able to complete group tasks or might not feel comfortable asking for help in class. Social anxiety can go along with or even lead to academic anxiety.

\section{RATIONALE OF THE STUDY}

The world today is a global village even in Mizoram, due to the globalization and advancement of technology becomes a high competition in education. Besides that, students at secondary stage 


\section{EPRA International Journal of Research and Development (IJRD)

who are adolescent having many confusions in their personal life. Students can feel easily anxiety related to every academic task. Some may only feel anxiety related to personal problem, and other may be academic tasks. Anxiety is not always negative. It can turn in to motivation for academic activity. There are many factors that increase anxiety among students that effect academic activities. There are ways to reduce anxiety in student So, the researcher is interested and felt that the importance to give sincere effort to study the Academic anxiety of Boys and Girls Students of Secondary School situated in Rural and Urban area.

\section{Objectives of the study}

1. To find out the level of Academic Anxiety of secondary school students in Aizawl District.

2. To compare Academic Anxiety of secondary school students in relation to gender.

3. To compare Academic Anxiety of secondary school students in relation to class.

Table 1

Distribution of sample of the study: $(\mathrm{N}=90)$

\begin{tabular}{|l|c|c|c|}
\hline \multicolumn{2}{|c|}{ VARIABLES } & NO. OF STUDENTS & PERCENTAGE \\
\hline \multirow{2}{*}{ SEX } & MALE & 47 & 52.22 \\
\cline { 2 - 4 } & FEMALE & 43 & 47.78 \\
\hline \multirow{2}{*}{ CLASS } & 9 & 45 & 50 \\
\cline { 2 - 4 } & 10 & 45 & 50 \\
\hline \multirow{2}{*}{ LOCALITY } & URBAN & 60 & 66.67 \\
\cline { 2 - 4 } & RURAL & 30 & 33.33 \\
\hline
\end{tabular}

\section{Tools Used}

Academic Anxiety Scale (AAA-Samrua) developed by Dr. Mohd. Abid Siddiqui and Dr. Atieq UI Rehman was used for collection of data. AAASamrua consists of 44 questions having three types of answer like Agree, Undicided Disagree. The items in the questions has 6 dimensions such as Academic Anxiety symptoms, Anxiety from poor study habits, Anxiety from subjects, Anxiety from school environment, Anxiety from teachers, Anxiety from examinations.

The reliability of the scale was decided by split-half method (odd-even). It was calculated on $\mathrm{N}=600$ and was found to be $\mathrm{r}=+0.85$ which is highly significant at 0.01 level of significance.

\section{Data Collection} standardized scale.

\section{Data Analysis} adopted.

\section{Analysis and Interpretation} with the objectives of the study as follows:
4. To compare Academic Anxiety of secondary school students in relation to locale.

\section{Hypotheses of the Study}

1. There is no significant difference between Academic Anxiety of male and female students of secondary school students in Aizawl district.

2. There is no significant difference between Academic Anxiety of class 9 and 10 students of secondary school students in Aizawl district.

3. There is no significant difference between Academic Anxiety of students of Rural and Urban secondary school students in Aizawl district.

\section{Population and Sample}

The population consists of Aizawl district high school students. The sample for the present study consists of 90 students in the academic year 2020-2021.

AAA-Samrua are administered among the secondary school students in Aizawl district, Mizoram. The scores were noted and calculated by following the norm of scoring given in manual of the

Statistical analysis through t-test was used to test the hypothesis. Percentage and mean were also

Analysis and interpretation are done in accordance

1. To investigate the level of Academic Anxiety of secondary school students in Aizawl. 
EPRA International Journal of Research and Development (IJRD)

Table 2

Level of Academic Anxiety of secondary school students

\begin{tabular}{|c|c|c|c|}
\hline SL.NO & LEVEL OF ACADEMIC ACHIVEMENT & NO. OF STUDENTS & PERCENTAGE \\
\hline 1 & EXTREMELY LOW & 0 & 0 \\
\hline 2 & LOW & 1 & 1.11 \\
\hline 3 & BELOW AVERAGE & 7 & 7.78 \\
\hline 4 & AVERAGE & 24 & 26.67 \\
\hline 5 & ABOVE AVERAGE & 42 & 46.66 \\
\hline 6 & HIGH & 16 & 17.78 \\
\hline 7 & EXTREMELY HIGH & 0 & 0 \\
\hline & & 90 & 100 \\
\hline
\end{tabular}

From the above table, 42 students on Above average, 24 students score on average, there are 16 students on high level, 7 students score below average, while only 1 student score low level, there is no students on the level of extremely low and extremly high.

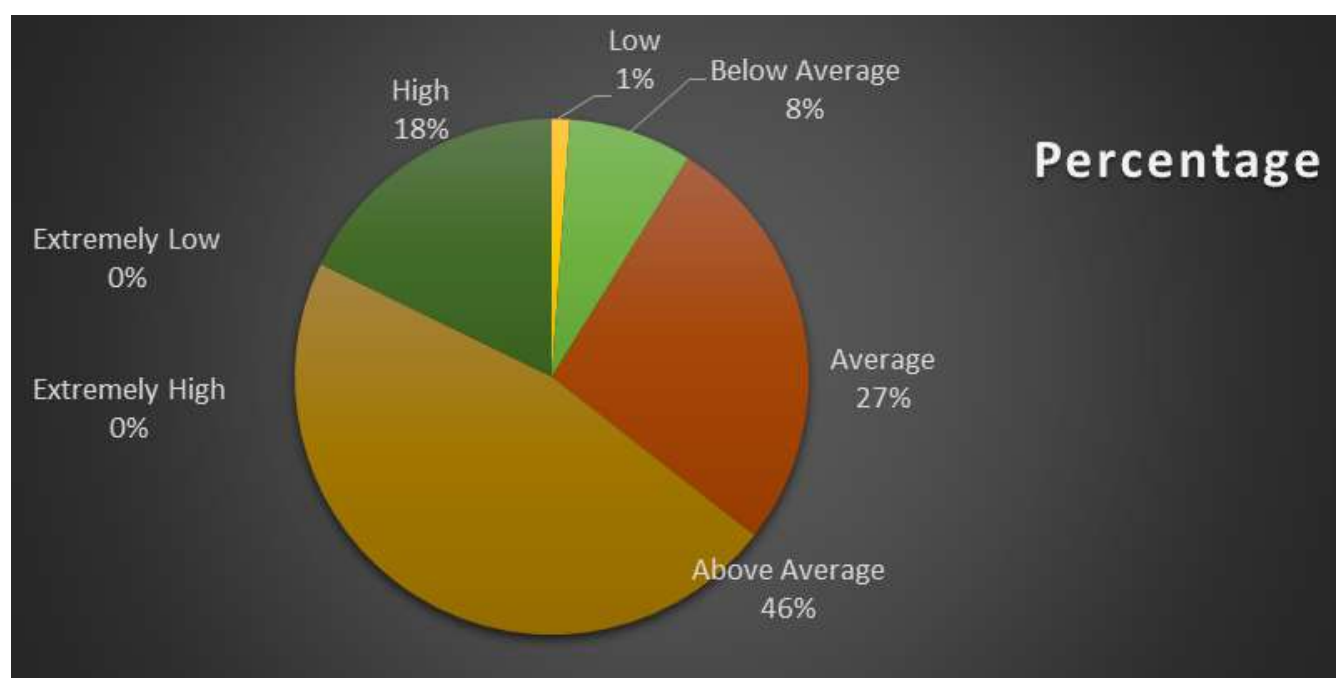

Figure 1: Percentage Scores of Academic Anxiety of the Students.

Table no. 2

Descriptive Statistics

\begin{tabular}{|c|c|c|c|c|}
\hline Range & Highest score & Lowest score & Mean & Mode \\
\hline 42 & 97 & 55 & 83.14 & 89 \\
\hline
\end{tabular}

Average score of 90 secondary school students is 83.14 which is the level of Above Average Academic Anxiety.

2. To compare Academic Anxiety of secondary school students in relation to Gender
$H_{0}$ 1: There is no significant difference between Academic Anxiety of male and female students of secondary school students in Aizawl district.

Table 3

Comparison of Academic Anxiety of Male and Female Students.

\begin{tabular}{|c|c|c|c|c|}
\hline Academic anxiety & $\mathbf{N}$ & Mean & t-value & $\begin{array}{c}\text { Level of } \\
\text { significant }\end{array}$ \\
\hline Male & 47 & 82.21 & 0.90 & N.S \\
\hline Female & 43 & 84.16 & & \\
\hline
\end{tabular}




\section{EPRA International Journal of Research and Development (IJRD)}

Analysis of data vide table no. 3 reflect the result for the test of significant differences between male and female students of secondary schools in relation to their level of Academic anxiety. The mean value for male and female students are 82.21 and 84.16 respectively. The table also reveals the t-value for the mean scores of male and female students towards Academic Anxiety level found to be 0.90 which is not significant.

Therefore, the null hypothesis no.1, there is no significant differences in the level of Academic Anxiety between male and female students of secondary schools is retained. This finding implies that Academic Anxiety level of male and female students are not significantly different. Male and female students are not differed significantly in their Academic Anxiety.

3. To compare Academic Anxiety of secondary school students in relation to Class.

$H_{0}$ 2: There is no significant difference between Academic Anxiety of class 9 and 10 students of secondary school students in Aizawl district.

Table 4

Comparison of Academic Anxiety of class 9 and class 10 Students.

\begin{tabular}{|c|c|c|c|c|}
\hline Academic anxiety & $\mathbf{N}$ & Mean & t-value & $\begin{array}{c}\text { Level of } \\
\text { significant }\end{array}$ \\
\hline Class 9 & 45 & 84.38 & 1.14 & N.S \\
\hline Class 10 & 45 & 81.91 & & \\
\hline
\end{tabular}

Analysis of data vide table no. 4 reflect the result for the test of significant differences between class 9 and class 10 students of secondary schools in relation to their level of Academic anxiety. The mean value for class 9 and class 10 students is 84.38 and 81.91 respectively. The table also reveals the t-value for the mean scores of class 9 and class 10 students towards Academic Anxiety level found to be 1.14 which is not significant.

Therefore, the null hypothesis no.2, there is no significant differences in the level of Academic Anxiety between class 9 and class 10 students of secondary schools is retained. This finding implies that Academic Anxiety level of class 9 and class 10 students are not significantly different. Class 9 and class 10 students are not differed significantly in their level of Academic Anxiety.

4. To compare Academic Anxiety of secondary school students in relation to Locality.

$H_{o} 3$. There is no significant difference between Academic Anxiety of students of Rural and Urban secondary school students in Aizawl district.

Table 5

Comparison of Academic Anxiety of Rural and Urban Students.

\begin{tabular}{|c|c|c|c|c|}
\hline Academic anxiety & $\mathbf{N}$ & Mean & t-value & $\begin{array}{c}\text { Level of } \\
\text { significant }\end{array}$ \\
\hline Rural & 30 & 80.17 & \multirow{2}{*}{1.08} & N.S \\
\hline Urban & 60 & 82.32 & & \\
\hline
\end{tabular}

Analysis of data vide table no. 5 reflect the result for the test of significant differences between Rural and Urban students of secondary schools in relation to their level of Academic anxiety. The mean value for class Rural and Urban students is 80.17 and 82.32 respectively. The table also reveals the t-value for the mean scores of Rural and Urban students towards Academic Anxiety level found to be 1.08 which is not significant.

Therefore, the null hypothesis no.3, there is no significant differences in the level of Academic Anxiety between Rural and Urban students of secondary schools is retained. This finding implies that Academic Anxiety level of Rural and Urban students are not significantly different. Rural and Urban students are not differed significantly in their level of Academic Anxiety

\section{MAJOR FINDINGS}

1. The result of the level of academic anxiety.
a) Above Average (46.66\%)
b) Average $(26.67 \%)$
c) High $(17.78 \%)$
d) Below Average (7.78\%)
e) Low (1.11\%)
f) Extremely low and Extremely High - 


\section{EPRA International Journal of Research and Development (IJRD)

2. There is no significant difference between Male and female, Class 9\&10, Rural and Urban area among secondary school students in Aizawl District.

\section{DISCUSSION}

- If the students in the secondary stage have more academic anxiety, they cannot perceive a proper learning and it can lead to intended to drop out of school.

- Teachers, School Administrator and Parents cooperation for management of Anxiety of the learners is required. Guidance and counselling class, good home environment, teacher and students' relationship, motivations etc. may be an important factor for elimination of academic anxiety among secondary students.

- Gender wise analysis of the study results reveals that there is no significant difference between male and female students in their level of Academic anxiety. Similar result was found by (Azeem 2018), (Roa \& Chaturvedi, 2017) in their Study of Academic Anxiety of Secondary School Students in Relation to Gender and Locality. Contradictory result was found by Sharma and Shakir (2019). It was found there was no significant difference between rural and urban areas' students of secondary school in their level of academic anxiety. Roa \& Chaturvedi (2017) found that contradictory results the difference of rural and urban area.

- There is no significant difference between class 9 and 10 students in the level of academic anxiety, this result reveals that class 10 students are generally older than class 9 but they are not mature on the way of performing in their academic activities.

\section{CONCLUSION}

Academic anxiety interfered directly or indirectly the level of academic achievement of the students. A study on Academic anxiety in relation to academic achievement can be taken up among secondary and higher secondary level also. An educational planner or administrator can be framed some policies regarding management of anxiety in secondary stage.

\section{REFERENCE}

1. Azeem, M. A. (2018). Study of Academic Anxiety and Academic Achievement of Secondary School Students. International Journal of Research in Social Sciences, 8(3), 147-161. Retrieved on 4 September 2018, from https://www.ijmra.us/project\%20doc/2018/IJRSS _MARCH2018/IJMRA13408.pdf

2. Kumar,A. (2013). Relationship of Academic Anxiety among Adolescents in Relation to their Home Environment. International journal for research in education 2(7). 32- 37.

3. Rao B. V., Ramana and Chaturvedi, Anjali(2017). Study the Academic Anxiety of Secondary School Students in Relation to Gender and Locality. IMPACT: International Journal of Research in Humanities, Arts and Literature (IMPACT: IJRHAL),5(12), 59-62 , SSRN: https://ssrn.com/abstract $=3094169$

4. Sharma, S. \& Shakir, M. (2019). A study of Academic Anxiety of Senior Secondary School Students in Relation to Locale and Type of School. Research and Reflections on Education 17 (4), 01-09. DOI: 10.13140/RG.2.2.35160.03846 